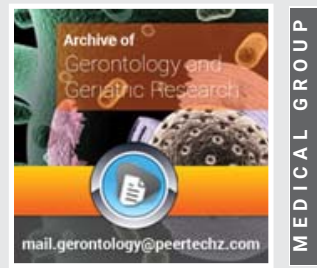

\section{Pierre A Guertin*}

University Laval and CHU de Québec, Canada

Dates: Received: 26 November, 2016; Accepted: 10 December, 2016; Published: 12 December, 2016

*Corresponding author: Pierre A. Guertin, Laval University/CHU de Québec, 2705 Laurier Boulevard, Quebec City, QC, Canada, G1V 4G2; Tel: 418.525.4444 (ext.48831); E-Mail: pierre.guertin@crchul.ulaval.ca

https://www.peertechz.com

\section{Editorial}

\section{Could Ageing-Related Chronic Skin Problems be Attributed to Neuronal and Non-Neuronal Dysfunctions?}

\begin{abstract}
The International League of Dermatological Societies (ILDS) has identified the consequences of skin ageing as one of the most important challenges in global skin health. As we get older, the skin undergoes indeed significant changes - many of which may be attributed to systemic, metabolic, hormonal and neuronal changes. As any other organ of the body, the skin is constituted of cells and systems that are, under physiological conditions, controlled by signals arising from the central, peripheral and autonomous nervous systems. Thus, several central nervous system (CNS) and non-CNS-mediated diseases and dysfunctions may lead secondarily to skin problems. The next-generation drugs and therapeutics for skin diseases will probably be increasingly acting upon central and peripheral mechanisms for superior efficacy which, in turn, shall force regulatory authorities to impose stricter regulations prior to approval of dermatological products.
\end{abstract}

\section{Editorial}

The skin is the largest organ $\left(\sim 2 \mathrm{~m}^{2}\right)$ of our body and the first line of defense from pathogens. It prevents excessive water content losses and, as such, serves as a lipid-rich structure involved in regulating body temperature. It is composed of four layers - namely the epidermis, basement membrane, dermis and subcutaneous (hypodermis). None of the epidermis sublayers (e.g., the stratum corneum or SC) contains blood vessels per se although the deepest layers are 'nourished' so to speak by diffusion from blood capillaries extending to the upper layers of the dermis. [1]. The dermis provides strength and elasticity to the skin through an extracellular matrix composed of collagen fibrils, microfibrils, and elastic fibers, embedded in hyaluronan and proteoglycans [2]. It harbors blood vessels, mechanoreceptors, thermoreceptors and nociceptors that provide the sense of touch, pressure and heat as well as biological fluids released from sudoriferous and sebaceous glands [3].

Dysfunctional skin is in fact associated with several debilitating pathological conditions such as xerosis, atopic dermatitis, atopic dermatitis, skin cancer, hemangioma, cold sore, acne vulgaris, sebaceous cyst, seborrheic keratosis, pilonidal sinus, ichthyosis vulgaris, psoriasis, rosacea, hives, vitiligo, lupus, eczema, impetigo, decubitus ulcer, bullous pemphigoid, epithelial skin cancer and pruritus, to name a few [4]. The ILDS has clearly reported that ageing-related skin problem is currently one of the most significant challenges in global skin health [5]. As we get older, the skin undergoes significant changes - many of which may be attributed to systemic, metabolic, hormonal, lifestyle, neuronal and nonneuronal diseases and dysfunctions. For instance, ageingrelated nerve degeneration has been found to affect sweat gland function (e.g., lower density, less cholinergic terminals, etc.) in rats [6] whereas, in humans, impaired neural control of mechanobiological processes altering skin function has been associated with ageing $[7,8]$. According to the World Health Organization, the number of people aged 65 or older is projected to grow from 524 million (2010) to nearly 1.5 billion in 2050 (who.int/ageing) but, the incidence of those who will be dealing with skin problems remains unknown.

Ageing is itself associated with so-called ageing diseases such as andropause, menopause, cancer, stroke, mobility impairment, paralysis, arthritis, Alzheimer's disease and dementia. Consequently, these conditions can also lead to skin problems - often chronic dry skin problems and itching (xerosis and pruritus, respectively) with or without inflammation and infection-contributing factors. In fact, associations have clearly been established between andropause, menopause, cancer, related-anabolic/sexual hormone dysregulations (e.g., estradiol, testosterone, dehydroepiandrosterone, growth hormone, insulin-like growth factor 1) and skin problems [9]. Other conditions that may lead, secondarily to skin problems include environment (pollution), climatic conditions (dry and 
cold air), lifestyle (low physical activity level), epigenetics, drug abuse, obesity, type II diabetes, pharmaceutical drugs, depression, paralysis, etc [6-13]. Regarding prevalence, according to data from NIAMS (National Institute of Arthritis and Musculoskeletal and Skin Disease), more than 5.5 million people in the U.S. suffer of psoriasis, 17 million live with acne and 5 million with vitiligo whereas, according to the British Skin Foundation, 8 million people in the U.K. are currently living with one of the skin diseases associated or not with ageing.

Unfortunately, most related mechanisms are, as of now, only considered as future cellular targets for next-generation CNS or non-CNS products against specific skin disease or dry skin problems. It will be pivotal for scientists to rapidly identify and develop potent therapies adapted to each condition for ensuring that skin and dry skin problems could, one day, be efficiently and safely treated.

\section{References}

1. McGrath JA, Eady RA, Pope FM (2004) Rook's Textbook of Dermatology (7th ed.). Blackwell Publishing 3.1-3.6.

2. Breitkreutz D, Mirancea N, Nischt R (2009) Basement membranes in skin: Unique matrix structures with diverse functions? Histochem Cell Biol 132: 1-10. Link: https://goo.gl/CrLtej

3. Nakamura K, Morrison SF (2008) A thermosensory pathway that controls body temperature. Nat Neurosci 11: 62-71. Link: https://goo.gl/LJ5RMx
4. Blume-Peytavi U, Kottner J, Sterry W, Hodin MW, Griffiths TW, et al. (2016) Age-Associated Skin Conditions and Diseases: Current Perspectives and Future Options. Gerontologist 56: S230-242. Link: https://goo.gl/0IPzL0

5. De Macedo GM, Nunes S, Barreto $T$ (2016) Skin disorders in diabetes mellitus: an epidemiology and physiopathology review. Diabetol Metab Syndr 8: 63 . Link: https://goo.gl/iSOFX3

6. Zouboulis CC (2004) Acne and sebaceous gland function. Clin Dermatol 22 360-366. Link: https://goo.gl/RWTcvm

7. Abdel-Rahman TA, Cowen $T$ (1994) Neurodegeneration in sweat glands and skin of aged rats. J Auton Nerv Syst 46: 55-63. Link: https://goo.gl/WsszZ7

8. Ogawa R, Hsu CK (2013) Mechanobiological dysregulation of the epidermins and dermis in skin disorders and in degeneration. $\mathrm{J}$ Cell Mol Med 17: 817-22. Link: https://goo.gl/cbqFBW

9. Makrantonaki E, Schonknecht $\mathrm{P}$, Hossini AM et al. (2010) Skin and brain age together: the role of hormones in the ageing process. Exp Gerontol 45: 801813. Link: https://goo.gl/oltkn5

10. Toyoda M, Nakamura M, Morohashi M (2002) Neuropeptides and sebaceous glands. Eur J Dermatol 12: 422-427. Link: https://goo.gl/X2vxdO

11. Danby SG (2016) Biological Variation in Skin Barrier Function: From A (Atopic Dermatitis) to X (Xerosis). Curr Probl Dermatol 49: 47-60. Link: https://goo.gl/ TX2cT4

12. Verkman AS (2009) Knock-out models reveal new aquaporin functions Handb Exp Pharmacol 190: 359-381. Link: https://goo.gl/LybW30

13. Russell M (2012) Assessing the relationship between vitamin D3 and stratum corneum hydration for the treatment of xerotic skin. Nutrients 4: 1213-1218. Link: https://goo.gl//Ou9Ep 